Supporting Information

\title{
Shape-designable liquid marbles stabilized by gel layer
}

Sajedeh Mahmoudi Salehabad, ${ }^{a}$ Saeid Azizian, ${ }^{* a}$ and Syuji Fujii ${ }^{b, c}$

${ }^{a}$ Department of Physical Chemistry, Faculty of Chemistry, Bu-Ali Sina University, Hamedan 65167, Iran.

E-mail:sazizian@basu.ac.ir andsdazizian@yahoo.com

${ }^{b}$ Department of Applied Chemistry, Faculty of Engineering, Osaka Institute of Technology 5-16-1, Omiya, Asahi-ku, Osaka 535-8585, Japan.

${ }^{c}$ Nanomaterials Microdevices Research Center, Osaka Institute of Technology 5-16-1, Omiya, Asahi-ku, Osaka 535-8585, Japan.

Number of pages: 10

Number of Figures: 10

Number of Tables: 3

Number of Videos: 2 


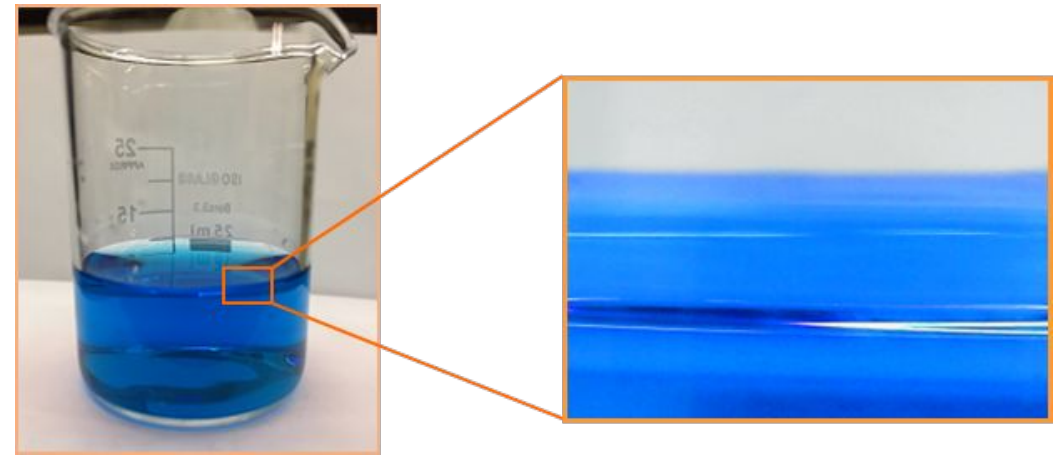

(a)

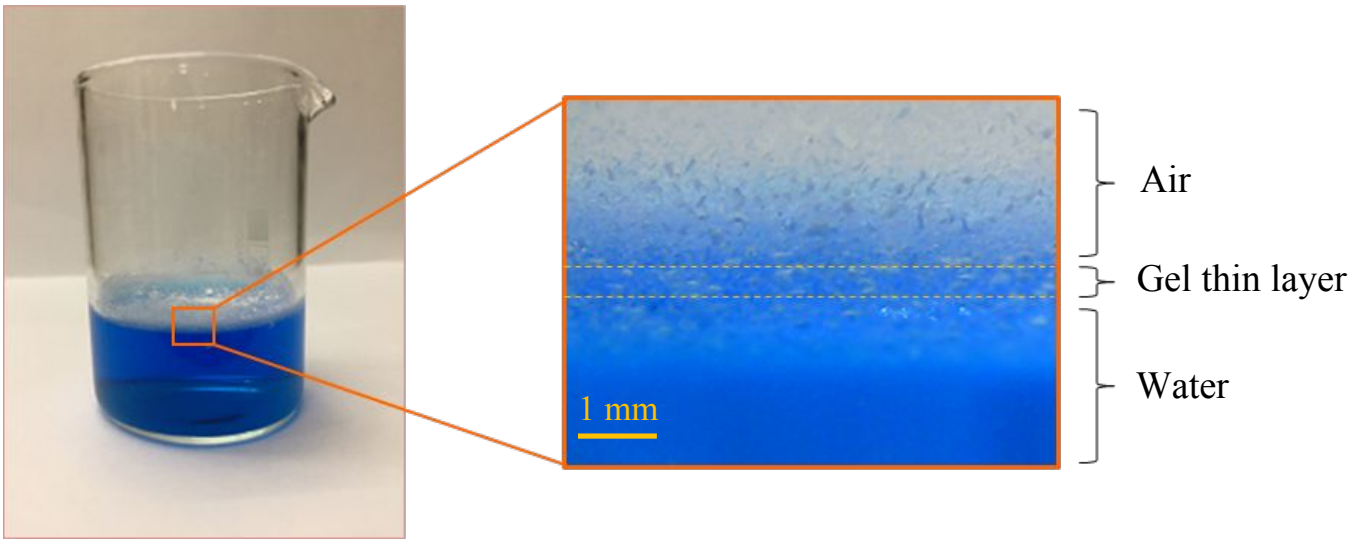

(b)

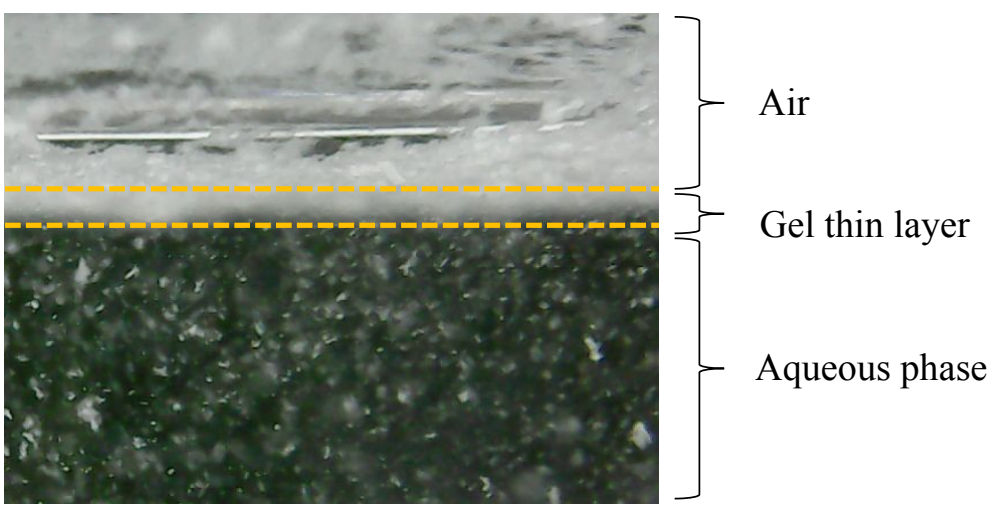

(c)

Figure S1. (a) The images of interfacial region for air/water system (b) The images of interfacial region for air/gel/water system and (c) The image of interfacial region for air/gel/water system at $\mathrm{pH}=12$ where the stearic acid particles dispersed in aqueous phase. 


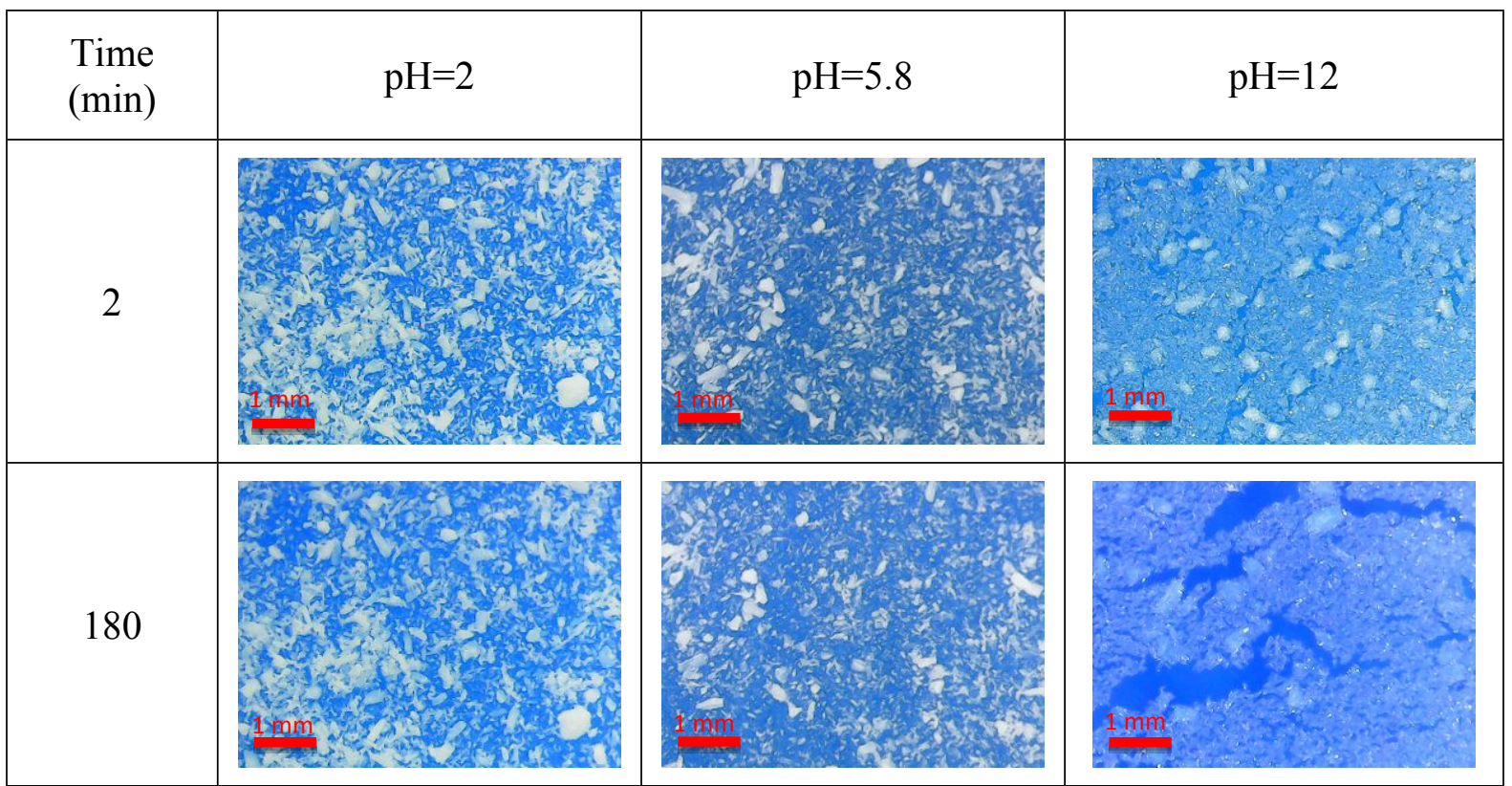

Figure S2. Optical micrographs of stearic acid gel layer formed on water surface with different $\mathrm{pH}$ values and different times (top view).

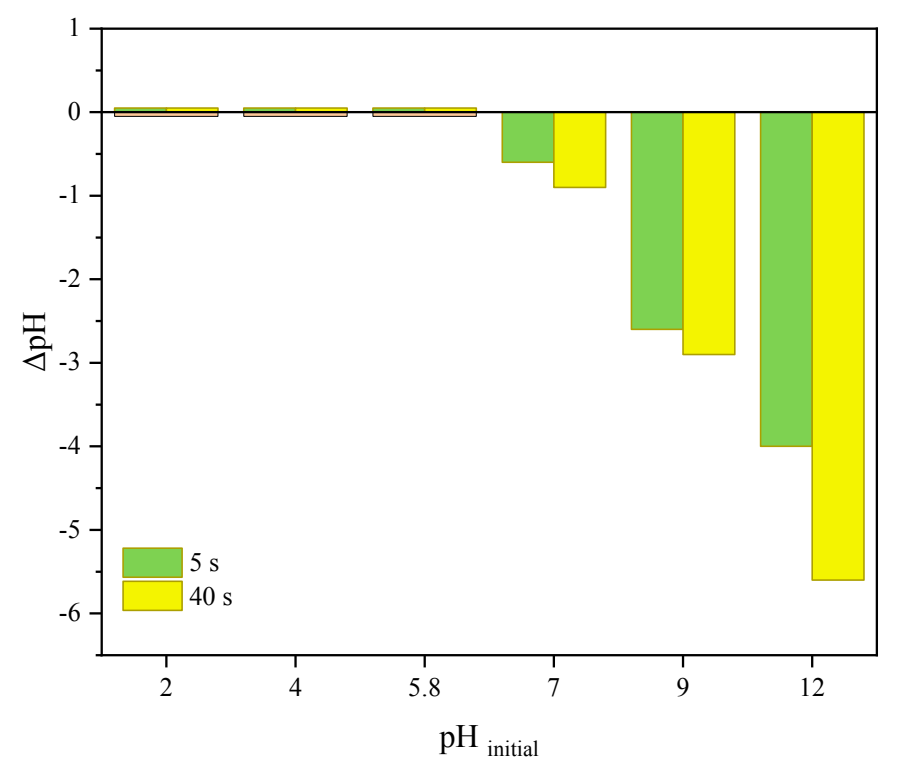

Figure S3. $\Delta \mathrm{pH}$ versus initial $\mathrm{pH}$ values of inner fluid of stearic acid-stabilized liquid marbles with different rolling time (5 and $40 \mathrm{~s})$. 


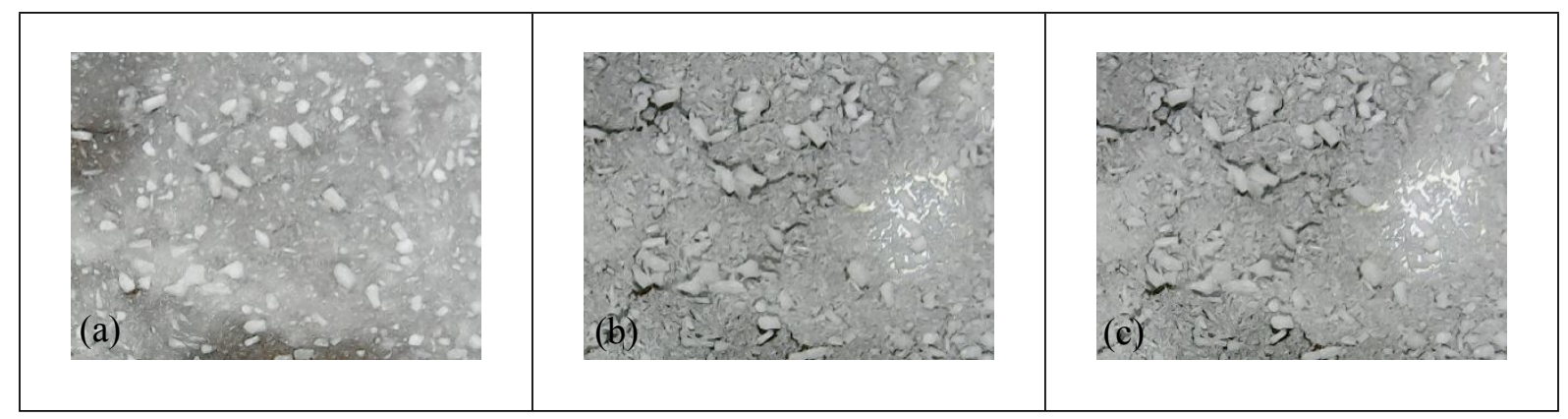

Figure S4. The images of deposited stearic acid gel layer on glass slide: (a) fresh gel layer, (b) after 25 min and (c) after $60 \mathrm{~min}$.

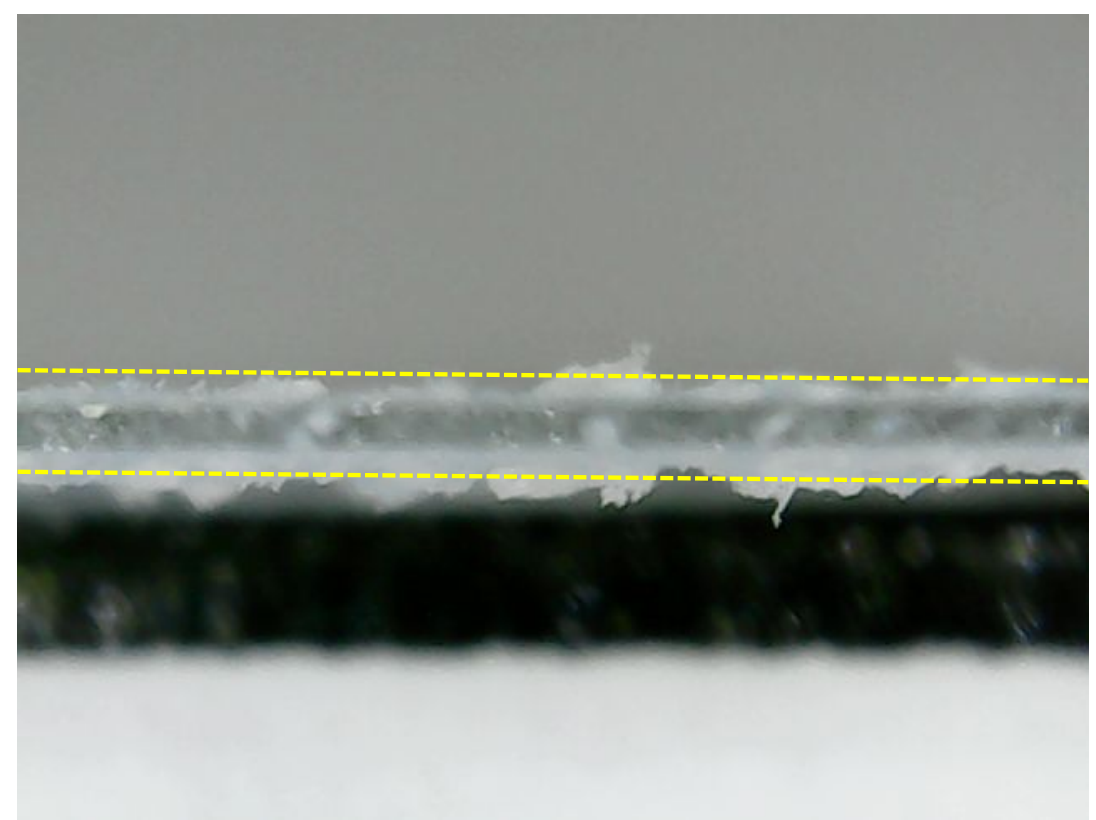

f Gel layer

Glass slide

Gel layer

Figure S5. Fresh gel layer of stearic acid deposited on glass slide. 


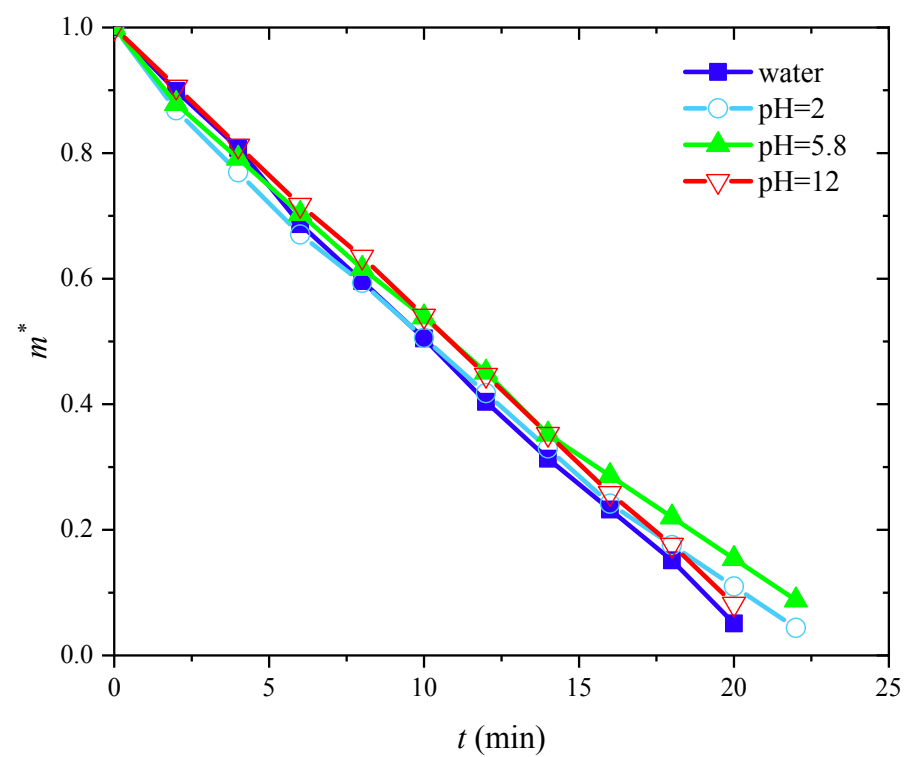

Figure S6. The evaporation rate of $5 \mu 1$ bare water droplet and $5 \mu 1$ stearic acid-stabilized liquid marbles at different $\mathrm{pH}$ values after $40 \mathrm{~s}$ rolling on stearic acid powder $\left(\mathrm{RH}=30 \%, \mathrm{~T}=29^{\circ} \mathrm{C}\right)$.

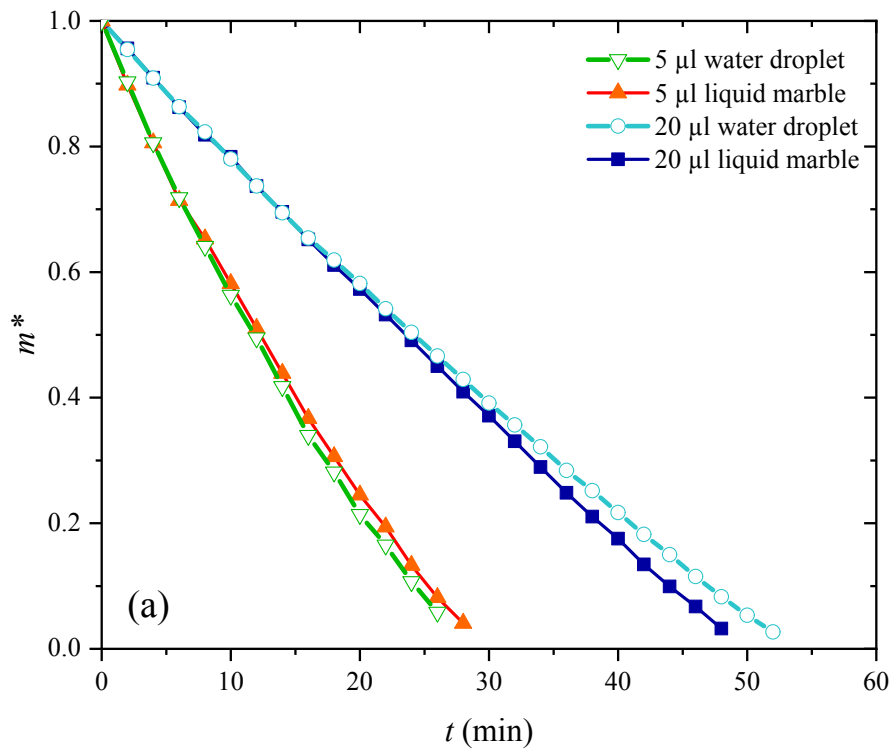



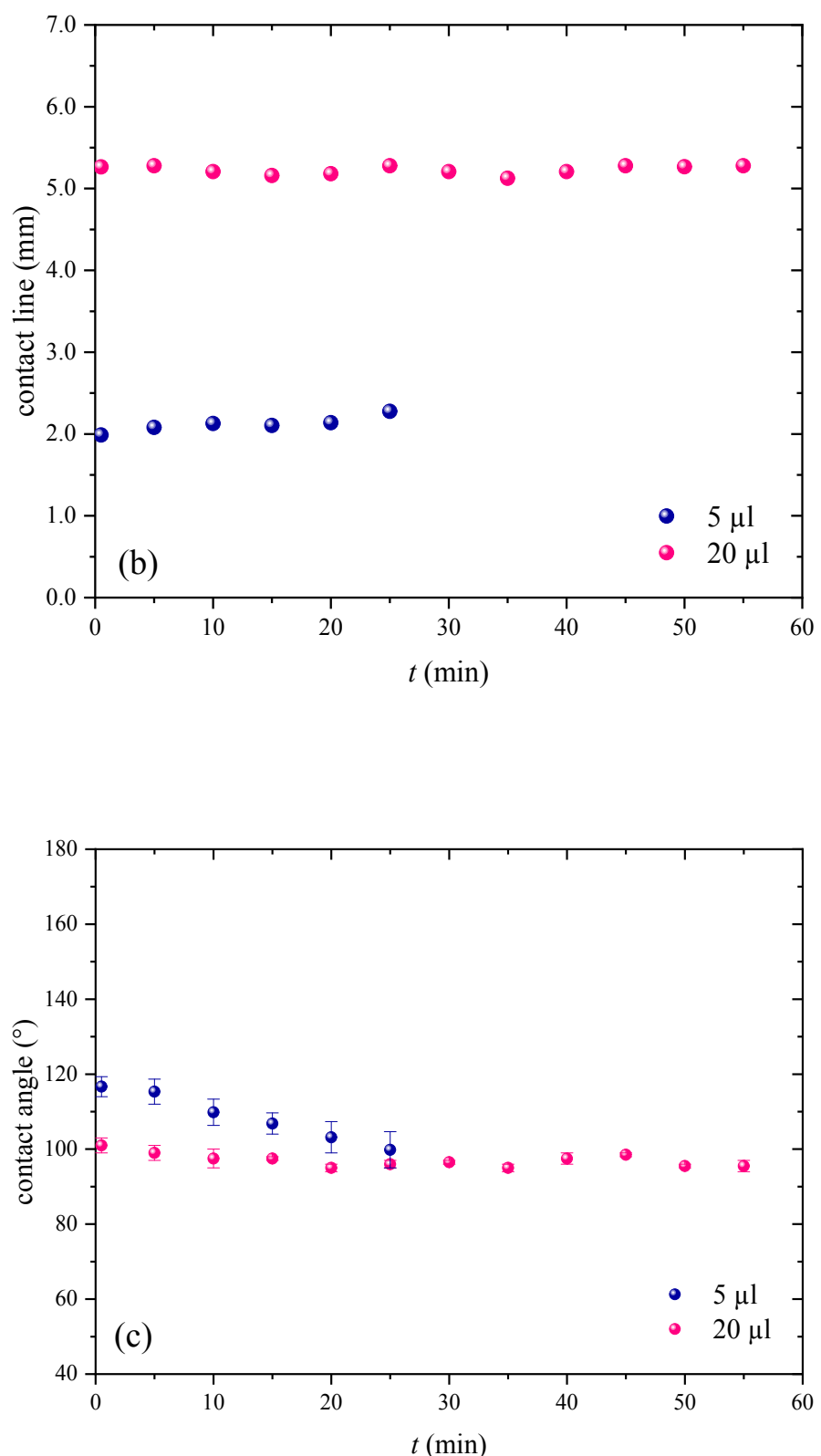

Figure S7. Measured parameters for evaporating liquid marbles fabricated using deionized water with different volumes after $40 \mathrm{~s}$ rolling on stearic acid powder $\left(\mathrm{RH}=22 \%, \mathrm{~T}=25^{\circ} \mathrm{C}\right)$. (a) Normalized mass, (b) contact line and (c) contact angle. 


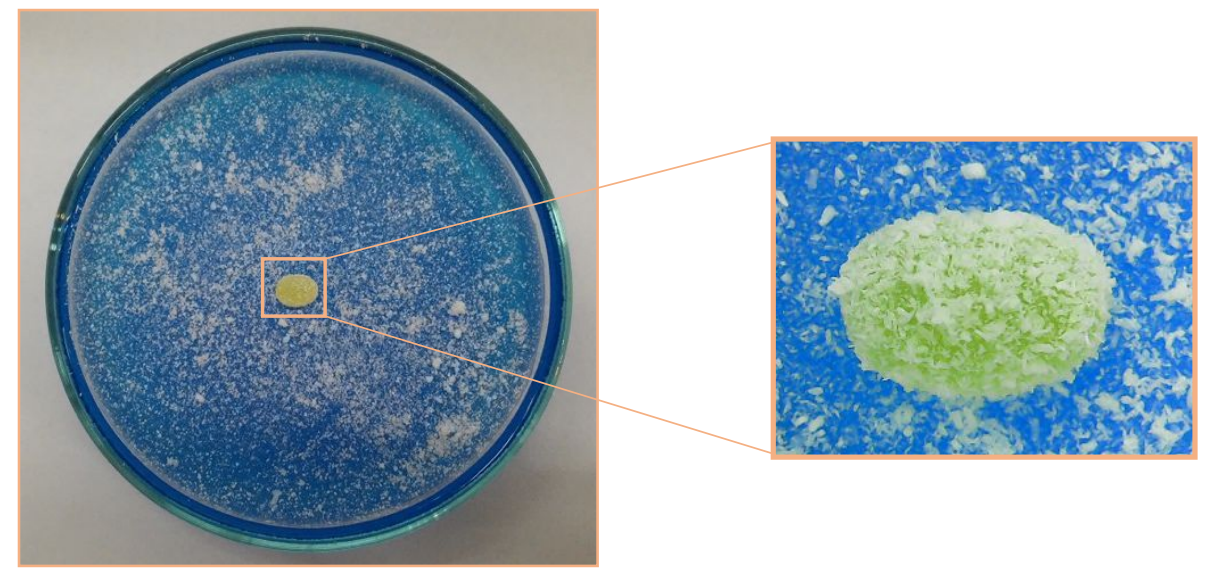

Figure S8. The floating liquid marble on the gel layer of stearic acid on water surface.

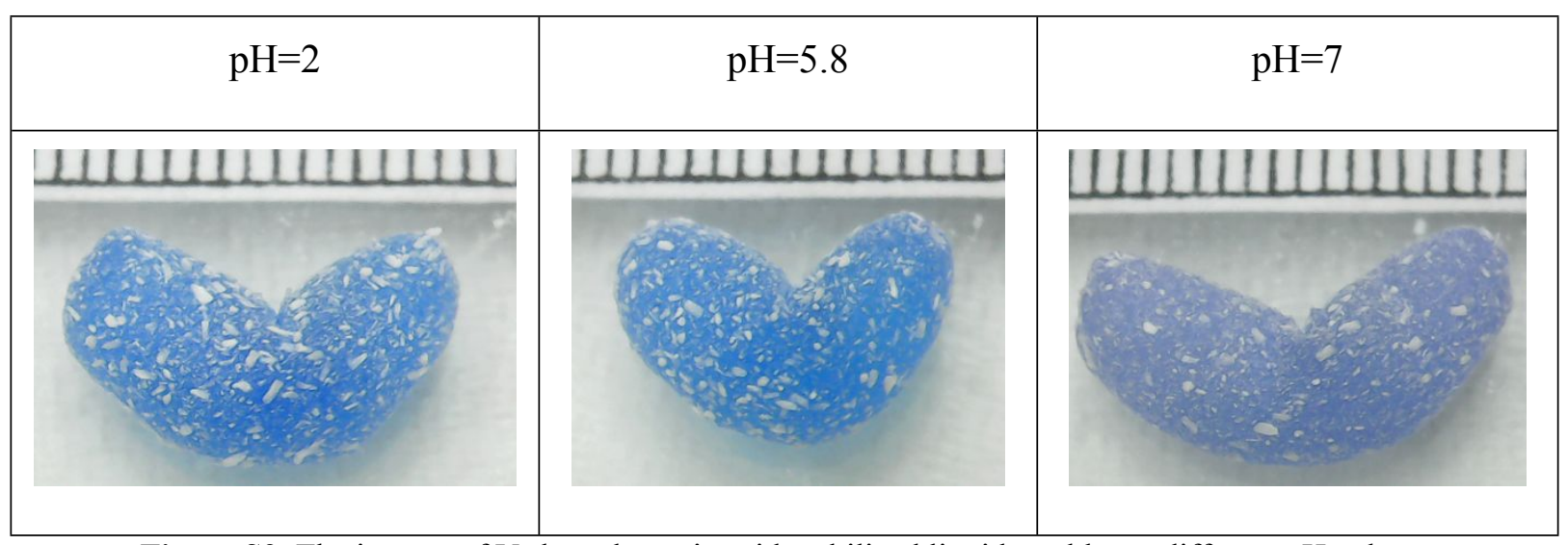

Figure S9. The images of V shaped stearic acid-stabilized liquid marbles at different $\mathrm{pH}$ values. 


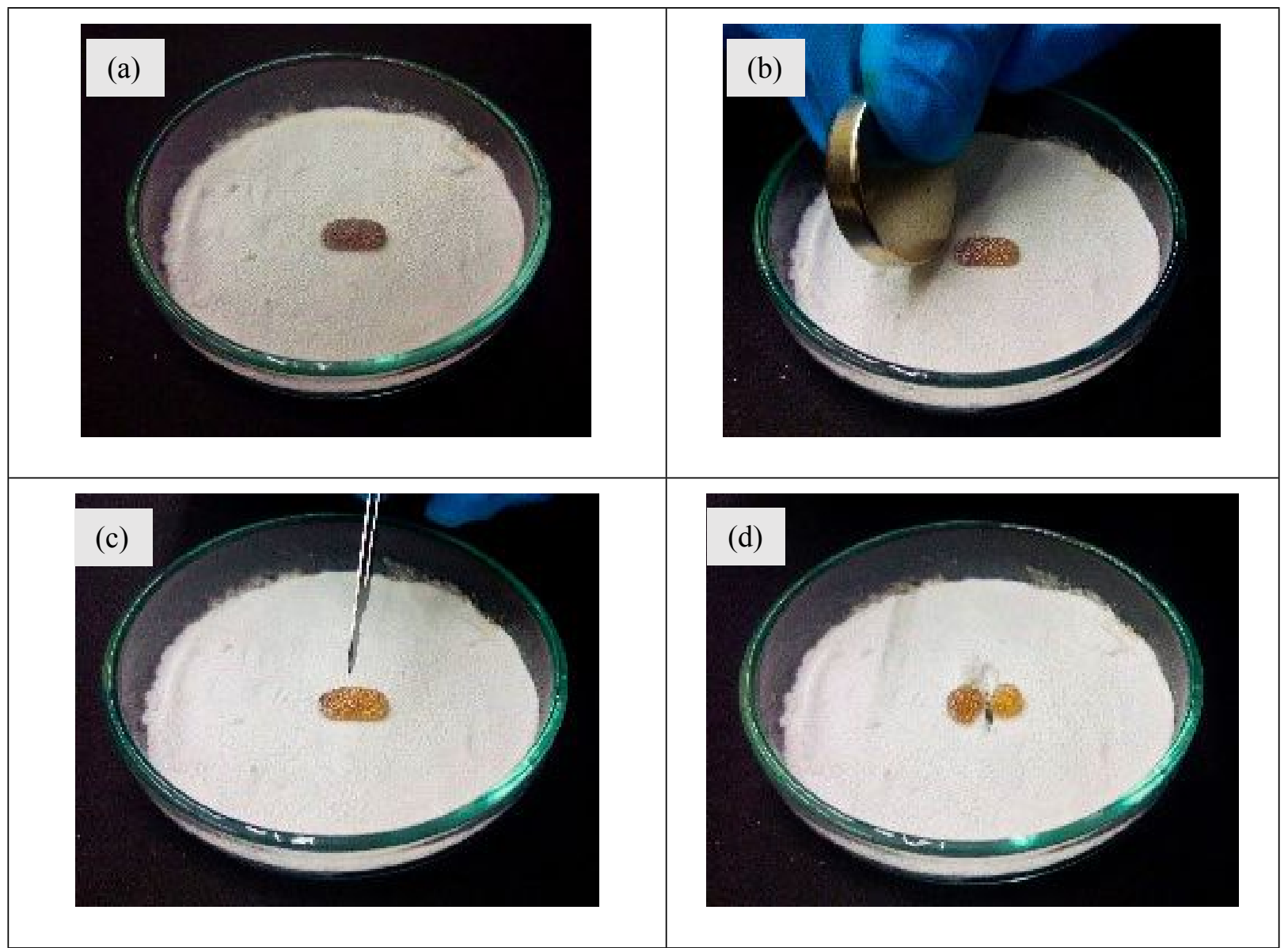

Figure S10. Magnetic separation of iron oxide particles dispersed in water in liquid marble. (a) A $100 \mu 1$ liquid marble prepared by iron oxide dispersed in water, (b) migration of iron oxide particles toward magnetic field, (c) and (d) the final liquid marble where cut with the scalpel. Iron oxide-rich liquid marble is dark-brown.

Table S1. The water content of stearic acid gel at different $\mathrm{pH}$ values.

\begin{tabular}{|c|c|c|c|c|}
\hline & $\mathrm{pH}=2$ & $\mathrm{pH}=5.8$ & $\mathrm{pH}=7$ & $\mathrm{pH}=12$ \\
\hline water content & $91 \%$ & $91 \%$ & $88 \%$ & $92 \%$ \\
\hline
\end{tabular}

Table S2. The evaporation rate of $5 \mu 1$ bare water droplet and $5 \mu 1$ stearic acid-stabilized liquid marbles with different $\mathrm{pH}$ values $\left(\mathrm{RH}=30 \%, \mathrm{~T}=29^{\circ} \mathrm{C}\right)$.

\begin{tabular}{|c|c|c|c|c|}
\hline & water droplet & $\mathrm{pH}=2$ & $\mathrm{pH}=5.8$ & $\mathrm{pH}=12$ \\
\hline $\begin{array}{c}d m * / d t \\
\left(\mathrm{~min}^{-1}\right)\end{array}$ & $-4.7 \times 10^{-2}$ & $-4.3 \times 10^{-2}$ & $-4.1 \times 10^{-2}$ & $-4.6 \times 10^{-2}$ \\
\hline
\end{tabular}


Table S3. The evaporation rate of bare water droplet and stearic acid-stabilized liquid marbles with different volumes $\left(\mathrm{RH}=22 \%, \mathrm{~T}=25^{\circ} \mathrm{C}\right)$.

\begin{tabular}{|c|c|c|c|c|}
\hline & $\begin{array}{c}5 \mu \mathrm{l} \text { water } \\
\text { droplet }\end{array}$ & $\begin{array}{c}5 \mu \mathrm{l} \text { liquid } \\
\text { marble }\end{array}$ & $\begin{array}{c}20 \mu \mathrm{l} \text { water } \\
\text { droplet }\end{array}$ & $\begin{array}{c}20 \mu 1 \text { liquid } \\
\text { marble }\end{array}$ \\
\hline $\begin{array}{c}d m^{*} / d t \\
\left(\mathrm{~min}^{-1}\right)\end{array}$ & $-3.5 \times 10^{-2}$ & $-3.3 \times 10^{-2}$ & $-1.9 \times 10^{-2}$ & $-2.0 \times 10^{-2}$ \\
\hline
\end{tabular}

Video S1. The water content of $30 \mu \mathrm{l}$ liquid marble $(\mathrm{pH}=5.8)$ after $10 \mathrm{~s}$ rolling on stearic acid powder, sucked with a syringe and deposited on hydrophobic surface.

Video S2. Cutting a $20 \mu 1$ liquid marble $(\mathrm{pH}=5.8)$ after $5 \mathrm{~s}$ rolling on stearic acid powder with the scalpel.

\section{Appendix 1}

For a liquid marble placed on the solid substrate, the Bond number is the ratio between gravitational energy and surface tension. So the Bond number is a function of liquid marble volume; based on scaling law ${ }^{1}$ for small liquid marbles $B o<<1$ and therefore the dimensionless height $h^{*}=h / r_{0} \approx 2$ is constant, but for large marbles ( $B o \geq 1$ ) with puddle shape by changing the volume of liquid marble the $h^{*}$ varies with Bond number as $h^{*} \sim B o^{-}$ 1/2. As explained, the shape of liquid marble which is deformed by rolling is determined by balance between rolling force and surface tension. Therefore, the Bond number for the deformable liquid marble by rolling can be given by

$B o_{t}=\frac{F_{m g}+F_{\text {roll }}}{F_{\gamma}}$

where $F_{m g}$ is the gravitational force, $F_{\text {roll }}$ is the rolling force and $F_{\gamma}$ is the surface tension force. By rearrangement of equation S1 one arrives

$B o_{t}=\frac{F_{m g}}{F_{\gamma}}+\frac{F_{\text {roll }}}{F_{\gamma}}$ 
$B o_{t}=B o+B o_{\text {roll }}$

where $B o$ is the usual Bond number and $B o_{\text {roll }}$ is the rolling Bond number. It was observed that by increasing the rolling time, deformation of liquid marble is more. So $F_{\text {roll }}$ is a function of $t_{\text {roll }}$; by considering a linear relationship Therefor equation $\mathrm{S} 3$ can be written as

$B o_{t}=B o+K t_{\text {roll }}$

where $K$ is a constant. So for a liquid marble with constant volume where $B o$ is constant, we have

$B o_{t} \sim t_{\text {roll }}$

Assuming $B o_{t} \sim h^{-1 / m}$ leads to

$h^{-1 / m} \sim t_{\text {roll }}$

where $h$ is the height of liquid marble. The height can be normalized by dividing to the radius of non-deformed liquid marble $r_{0}$. Therefor the dimensionless height of the deformed liquid marbles $\left(h^{*}\right)$ scales as

$h^{*} \sim t_{\text {roll }}^{-m}$

\section{References}

[1] Nguyen, N. T. Deformation of ferrofluid marbles in the presence of a permanent magnet.

Langmuir. 2013, 29, 13982-13989. 